\title{
Eriodictyol exerts potent anticancer activity against A549 human lung cancer cell line by inducing mitochondrial-mediated apoptosis, G2/M cell cycle arrest and inhibition of $\mathrm{m}$-TOR/PI3K/Akt signalling pathway
}

\author{
Yong Zhang ${ }^{1}$, Rui Zhang ${ }^{2}$, Huanjuan $\mathrm{Ni}^{3}$
}

\author{
1'Department of Respiratory Medicine, The Affiliated Hospital of Panzhihua University, \\ Panzhihua, China \\ 2Department of Respiratory Medicine, The First Affiliated Hospital of Chongqing \\ Medical University, Chongqing, China \\ ${ }^{3}$ Department of Emergency, The Affiliated Hospital of Panzhihua University, \\ Panzhihua, China
}

Submitted: 28 April 2017

Accepted: 7 July 2017

Arch Med Sci 2020; 16 (2): 446-452

DOI: https://doi.org/10.5114/aoms.2019.85152

Copyright $\odot 2019$ Termedia \& Banach

\section{Abstract}

Introduction: Eriodictyol is an important flavonoid and is commonly present across the plant kingdom. Flavonoids have been reported to show incredible pharmacological potential. However, the anticancer activity of the important flavonoid eriodictyol has not been well reported. In the present study we determined its anticancer potential against the human lung cancer cell line A549.

Material and methods: The initial cytotoxicity induced by eriodictyol was measured by MTT assay. Flow cytometry was used to study the effects of eriodictyol on apoptosis, cell cycle phase distribution and mitochondrial membrane potential loss. The comet assay was used to measure DNA damage induced by eriodictyol in cancer cells while the western blot assay indicated effects of the compound on Bax/Blc-2 and PI3K/AKT/m-TOR proteins.

Results: The results showed that eriodictyol has an $\mathrm{IC}_{50}$ value of $50 \mu \mathrm{M}$ against human lung cancer cells as compared to the $\mathrm{IC}_{50}$ of $95 \mu \mathrm{M}$ against non-cancerous FR2 cells. The molecule exerted its anticancer activity through induction of apoptosis by regulating the $\mathrm{Bcl}-2 / \mathrm{Bax}$ signalling pathway. It caused cell cycle arrest of human lung cancer A549 cells at G2/M phase. Eriodictyol was also found to cause a reduction of the mitochondrial membrane potential in a dose-dependent manner. Additionally, eriodictyol effectively inhibited the mTOR/PI3K/Akt signalling pathway in a dose-dependent manner.

Conclusions: Based on the above findings, we conclude that eriodictyol exerts its anticancer activity through induction of mitochondrial apoptosis and G2/M cell cycle arrest and inhibition of the TOR/PI3K/Akt cascade, indicating that it may have potential as a lead compound in the treatment of lung cancer, provided further in depth studies are done.

Key words: lung cancer, eriodictyol, apoptosis, cell cycle arrest, flow cytometer.

\author{
Corresponding author: \\ Yong Zhang \\ Department \\ of Respiratory Medicine \\ The Affiliated Hospital \\ of Panzhihua University \\ Panzhihua \\ 617000, China \\ Phone/fax: \\ +860812 2213492 \\ E-mail: yongzhang33@ \\ hotmail.com
}




\section{Introduction}

Flavonoids are commonly present across the plant kingdom and have been reported to exhibit tremendous pharmacological potential. A diversity of medicinal plants showing the presence of high amounts of flavonoids have been used in several traditional systems of medicine for the treatment of several diseases and disorders. The medicinal properties of these plants are mainly due to the presence of these secondary metabolites [1, 2]. Among natural products, flavonoids represent an important part of the human diet, and in the United States the estimated regular dietary intake of mixed flavonoids is up to $1 \mathrm{~g}$. This figure may be even higher for people improving their diets with flavonoid-rich herbal preparations [3]. With advances in medical research, flavonoids are being evaluated for their diverse bioactivities. So far they have been reported to exhibit a wide range of activities - anti-inflammatory, estrogenic, enzyme inhibition, antimicrobial, anti-allergic, antioxidant, antitumor and others [4]. Owing to their fairly consistent structure, flavonoids impede the activity of a wide range of eukaryotic enzymes and therefore exhibit diversity of activities. The different parts of the flavonoid molecules have been considered critical for their bioactivities [4]. The present study was therefore designed to evaluate the anticancer potential of eriodictyol (Figure 1) against the human lung cancer cell line A549 and to decipher the underlying mechanism. Lung cancer is the major cause of cancer related deaths in the world and in China $[5,6]$. The severe increase in the incidence of cancers, the dearth of suitable cures and the severe side effects accompanying the synthetic drugs have made it necessary to explore new and more effective molecules. With the upsurge in the incidence of drug resistance, the treatment and management of cancers has become even more difficult $[5,6]$. In the current study eriodictyol was evaluated against human lung cancer cells and it was found to exhibit an $\mathrm{IC}_{50}$ of $50 \mu \mathrm{M}$. The results of the present study indicated that eriodictyol exhibits significant anticancer activity by inducing apoptosis in human lung cancer A549 cancer cells, altering mitochondrial membrane potential (MMP) and causing cell cycle arrest via downregulation of the expression of $\mathrm{Bcl}-2$ and upregulation of Bax expression. In conclusion, we propose that eriodictyol may prove to be a potential candidate for the development of anticancer chemotherapy for lung cancer.

\section{Material and methods}

\section{Chemical reagents, cell lines and culture conditions}

All chemicals and reagents including eriodictyol ( $98 \%$ pure by HPLC) were obtained from
Sigma-Aldrich. Human lung cancer (A549) and non-cancerous human epithelial FR2 cell lines were purchased from the Type Culture Collection of the Chinese Academy of Sciences, Shanghai, China. The cells were cultured in RPMI- 1640 medium containing $10 \%$ fetal bovine serum, $100 \mathrm{U} / \mathrm{ml}$ penicillin and $100 \mu \mathrm{g} / \mathrm{ml}$ streptomycin and maintained in a humidified atmosphere containing $5 \% \mathrm{CO}_{2}$. All of the reagents were procured from Hyclone (Logan, UT, USA).

\section{Anti-proliferative assay}

MTT was used to determine the anti-proliferative activity of eriodictyol against the human lung cancer A549 cells [7]. The A549 cells in $100 \mu \mathrm{l}$ of culture medium were seeded in a 96 -well plate at a density of $3 \times 10^{3}$ cells $/ \mathrm{ml}$ and kept at $37^{\circ} \mathrm{C}$ in $5 \% \mathrm{CO}_{2}$ for $48 \mathrm{~h}$. After $24 \mathrm{~h}$, an additional $100 \mu \mathrm{l}$ of complete medium with either no additions or different concentrations $(0-100 \mu \mathrm{M})$ of eriodictyol was added. Thereafter, the cells were incubated for 12, 24, and $48 \mathrm{~h}$. This was followed by the addition of $20 \mu \mathrm{l}$ of MTT solution $(5 \mathrm{mg} / \mathrm{ml}$ ) and incubation for $4 \mathrm{~h}$. Afterwards the medium was removed and $150 \mu \mathrm{l}$ of DMSO added. The absorbance (OD) of each well was measured at $490 \mathrm{~nm}$ using a Tunable Mi-185 croplate Reader (EL-x 800, BioTek Instruments, USA).

\section{Determination of apoptotic populations and DNA damage}

Human A549 cells at a density of $2 \times 10^{5}$ cells/ well were seeded in 6-well plates and then administered with $0,25,50$ and $100 \mu \mathrm{M}$ eriodictyol for $48 \mathrm{~h}$. For estimation of apoptotic cell populations an FITC-Annexin V/PI Apoptosis detection kit was used following the manufacturer's instructions (Beijing Biosea Biotechnology, China). The alkaline comet assay was carried out to evaluate DNA damage efficacy of eriodictyol as described previously $[8,9]$.

\section{Cell cycle analysis}

For cell cycle analysis the A549 cells were treated with $0,25,50$ and $100 \mu \mathrm{M}$ eriodictyol concentration of KAM and the percentage of cells in each of the cell cycle phases was estimated using<smiles>O=C1C[C@H](c2ccc(O)c(O)c2)Oc2cc(O)cc(O)c21</smiles>

Figure 1. Chemical structure of eriodictyol 
the Muse Cell Analyzer and Muse Cell Cycle Kit according to the manufacturer's protocol (Merck Millipore).

\section{Mitochondrial membrane potential (MMP)}

Human lung cancer A549 cells were seeded at a density of $2 \times 10^{5}$ cells/well in a 6 -well plate and kept for $24 \mathrm{~h}$ and treated with $0,25,50$ and $100 \mu \mathrm{M}$ of the test compound for $48 \mathrm{~h}$ at $37^{\circ} \mathrm{C}$ in $5 \% \mathrm{CO}_{2}$ and $95 \%$ air. Afterwards, the cells from all treatments were collected, washed twice with PBS and re-suspended in $500 \mu \mathrm{l}$ of $\mathrm{DOC}_{6}(1 \mu \mathrm{mol} / \mathrm{l})$ for MMP at $37^{\circ} \mathrm{C}$ in a dark room for $30 \mathrm{~min}$. The samples were then analyzed instantly using flow cytometry.

\section{Western blotting analysis}

After administration with various concentrations of eriodictyol, cells were harvested and lysed in lysis buffer $(20 \mathrm{mM} \mathrm{HEPES}, 350 \mathrm{mM} \mathrm{NaCl}$, $20 \%$ glycerol, $1 \%$ Nonidet P 40, $1 \mathrm{mM} \mathrm{MgCl}, 0.5$ mM EDTA, 0.1 mM EGTA, 1 mM DTT, 1 mM PMSF, protease inhibitor cocktail, and phosphatase inhibitor cocktail). Out of the total protein samples a $20 \mu \mathrm{g}$ aliquot was separated on $10 \%$ SDS-PAGE gel. The gel was then transferred to nitrocellulose membranes, blocked with 5\% BSA and probed with a primary antibody. This was followed by probing with the required secondary antibody. Finally, the signal was perceived with WESTSAVE Up luminal-based ECL reagent (ABFrontier, Korea).

\section{Statistical analysis}

All experiments were carried out in triplicate and the results were expressed as mean \pm standard deviation (SD). The values were considered significant at $p^{\star}<0.05$ and $p^{\star *}<0.01$. The statistical analysis was carried out by Student's $t$ test using GraphPad prism 7 software.

\section{Results}

Anticancer activity of eriodictyol on A549 human lung cancer cells

Anticancer activity of eriodictyol (Figure 1) was evaluated against human A549 cancer and noncancerous FR2 cells. The MTT assay at 0-100 $\mu \mathrm{M}$ concentration showed that eriodictyol exhibited a concentration-dependent activity. The $\mathrm{IC}_{50}$ of eriodictyol against human A549 cells was found to be $\mathrm{IC}_{50} 50 \mu \mathrm{M}$ (Figure $2 \mathrm{~A}$ ) as against the $\mathrm{IC}_{50}$ of $95 \mu \mathrm{M}$ against the noncancerous FR2 cells (Figure 2 B).

\section{Eriodictyol caused apoptosis and DNA damage in human A549 lung cancer cells}

In order to confirm apoptotic cell death induced by eriodictyol annexin V/PI staining was carried out at the concentrations of $0,25,50$ and $100 \mu \mathrm{M}$. Flow cytometric results showed that the percentage of apoptotic cell population increased to $9.7 \%$, $27.4 \%$ and $39.5 \%$ in human A549 cancer cells after $48 \mathrm{~h}$ at the concentrations of 25,50 and $100 \mu \mathrm{M}$, respectively, as compared to the untreated control (Figure 3). Thus the results indicate that eriodictyol caused apoptotic cell death of human A549 cancer in a concentration-dependent manner. Furthermore, the results of the comet assay showed that eriodictyol caused DNA damage in A549 human lung cancer cells dose dependably (Figure 4) and the DANA damage increased with the increasing concentration of the drug.

\section{G2/M phase arrest of A549 cancer cells triggered by eriodictyol}

Our results indicated that eriodictyol caused G2/M cell cycle arrest in a dose. It was observed that the percentage of cells was considerably increased in G2/M at the concentrations of 0 to $100 \mu \mathrm{M}$ of eriodictyol, causing G2/M arrest (Figure 5). Additionally, the populations of A549 cells
A

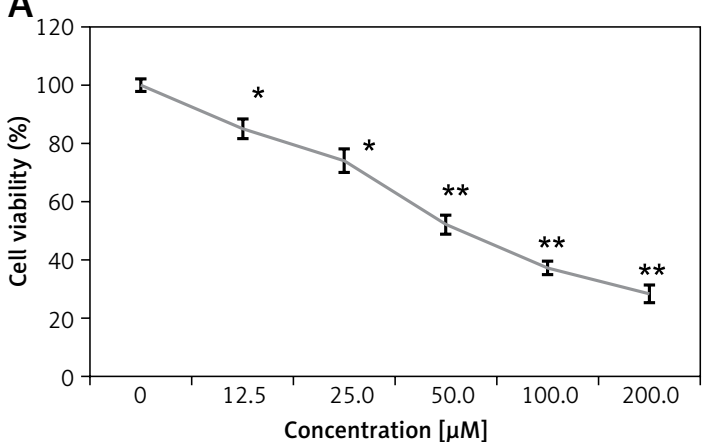

B

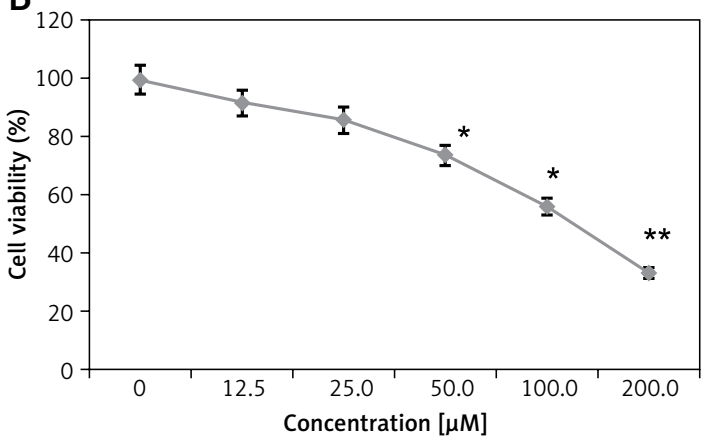

Figure 2. Effect of eriodictyol on viability of (A) human A549 lung cancer and (B) non-cancerous FR2 cell lines at $48 \mathrm{~h}$ of incubation. All experiments are representatives of three biological replicates \pm SD

Results were considered significant at $p^{*}<0.05$ and $p^{* *}<0.01$ 
Eriodictyol exerts potent anticancer activity against A549 human lung cancer cell line by inducing mitochondrial-mediated apoptosis, G2/M cell cycle arrest and inhibition of m-TOR/PI3K/Akt signalling pathway
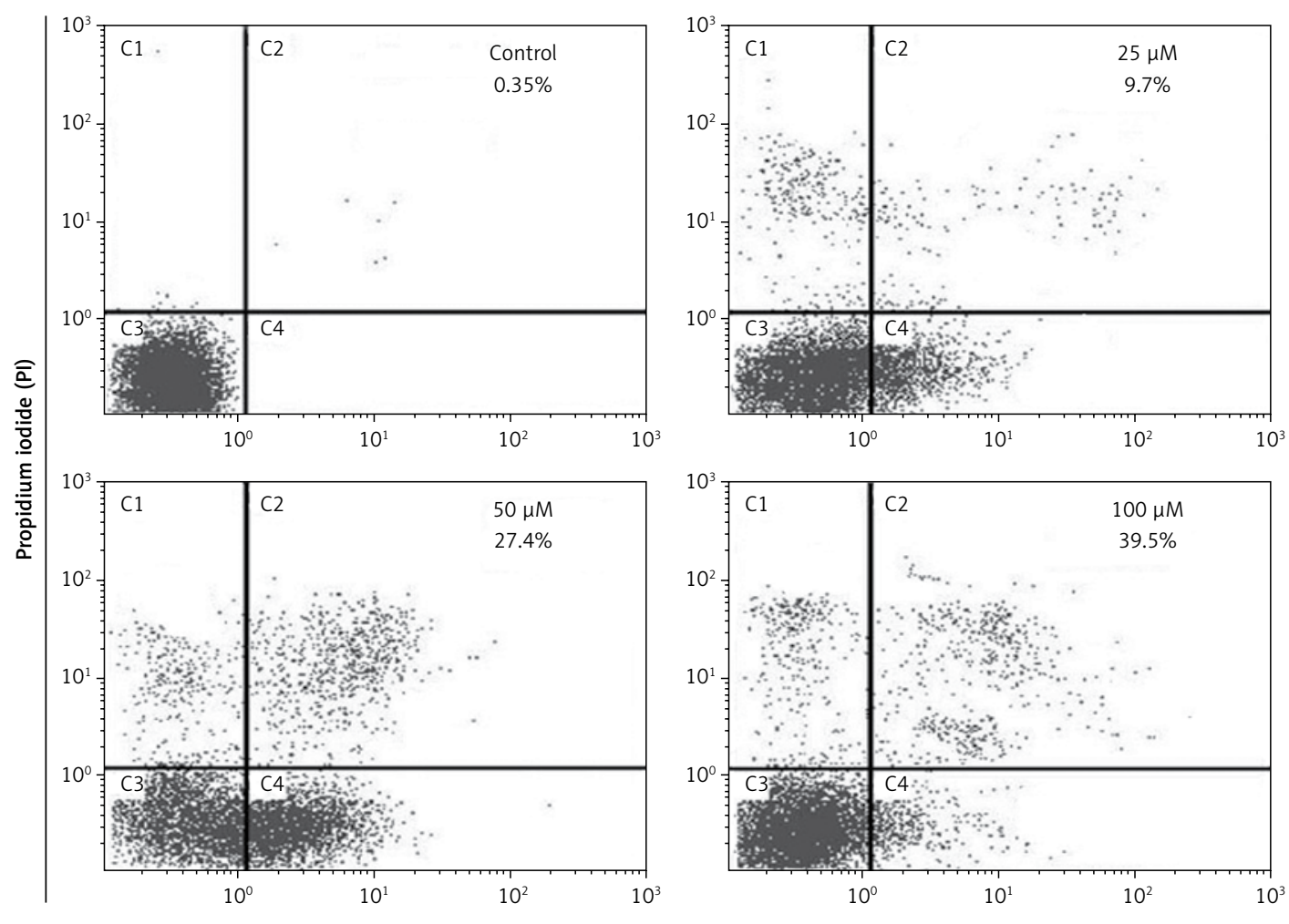

Annexin V-FITC

Figure 3. Induction of apoptosis by eriodictyol at the indicated doses by Annexin V/PI staining observed by flow cytometry. All experiments are representatives of three biological replicates

in $\mathrm{G} 2 / \mathrm{M}$ phase were only slightly elevated at the concentration of $50 \mu \mathrm{M}$. Moreover, the eriodica dose of $25 \mu \mathrm{M}$. However, the apoptotic cell populations significantly increased at $\mathrm{G} 2 / \mathrm{M}$ phase at tyol induced G2/M phase increase of A549 cancer cells showed a dose-dependent trend.

Control

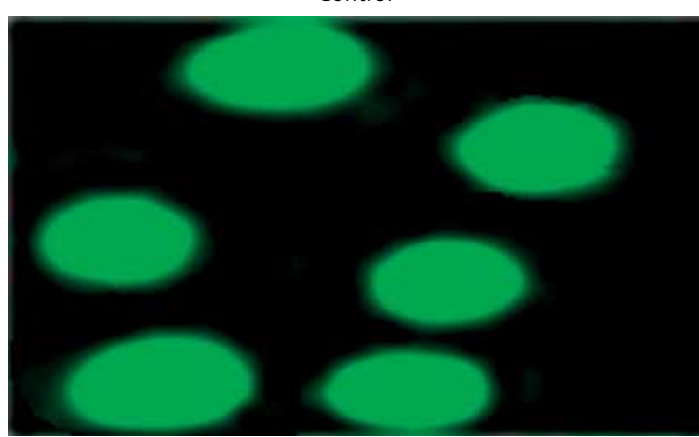

$50 \mu \mathrm{M}$

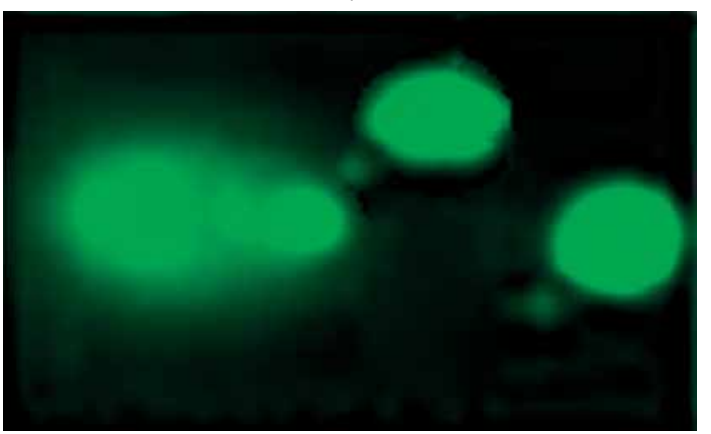

$25 \mu \mathrm{M}$

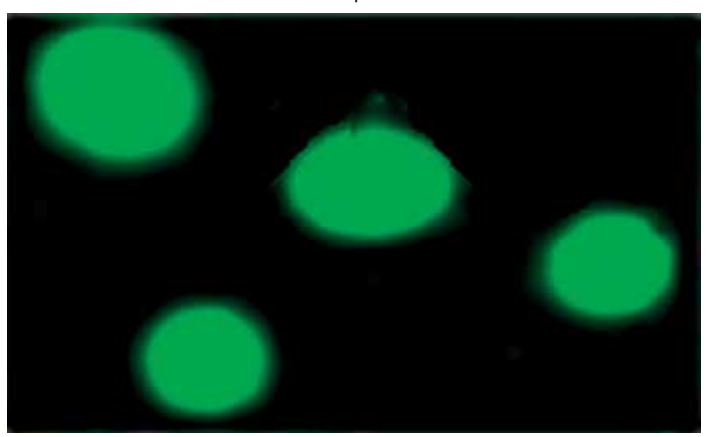

$100 \mu \mathrm{M}$

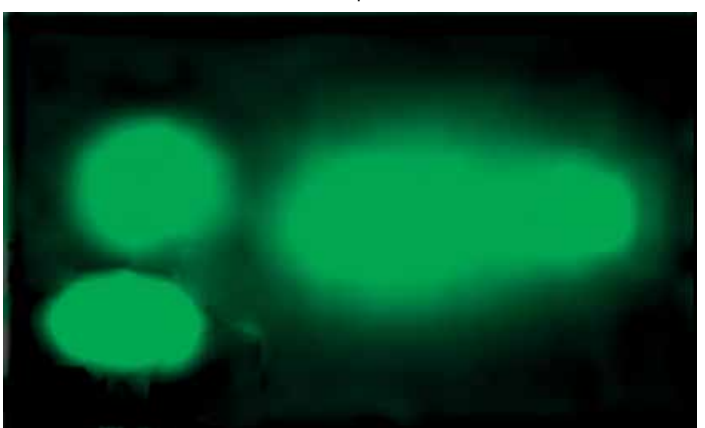

Figure 4. Induction of DNA damage at the indicated doses of eriodictyol by comet assay. All experiments are representatives of three biological replicates 


\section{MMP loss in human A549 lung cancer cells}

Cells were administered with $0,25,50$ and $100 \mu \mathrm{M}$ eriodictyol for various time periods and the levels MMP were evaluated. A significant reduction of MMP level (Figure $6 \mathrm{~A}$ ) was observed in the treated A549 cells as compared to the control. At concentrations of $0,25,50$ and $100 \mu \mathrm{M}$, the MMP was found to be 81,52 and $33 \%$ as compared to the untreated human A549 cancer cells.

\section{Effect of eriodictyol on Bcl-2/Bax signalling} pathway

To evaluate whether eriodictyol could induce apoptosis, the expression of pro-apoptotic proteins $\mathrm{Bcl}-2 / \mathrm{Bax}$ was evaluated using western blot assay. The findings are shown in Figure $6 \mathrm{~B}$ and indicate an interesting outcome. The increased Bax/Bcl-2 ratio causes activation of caspase 3 and hence apoptosis. In our results, compared

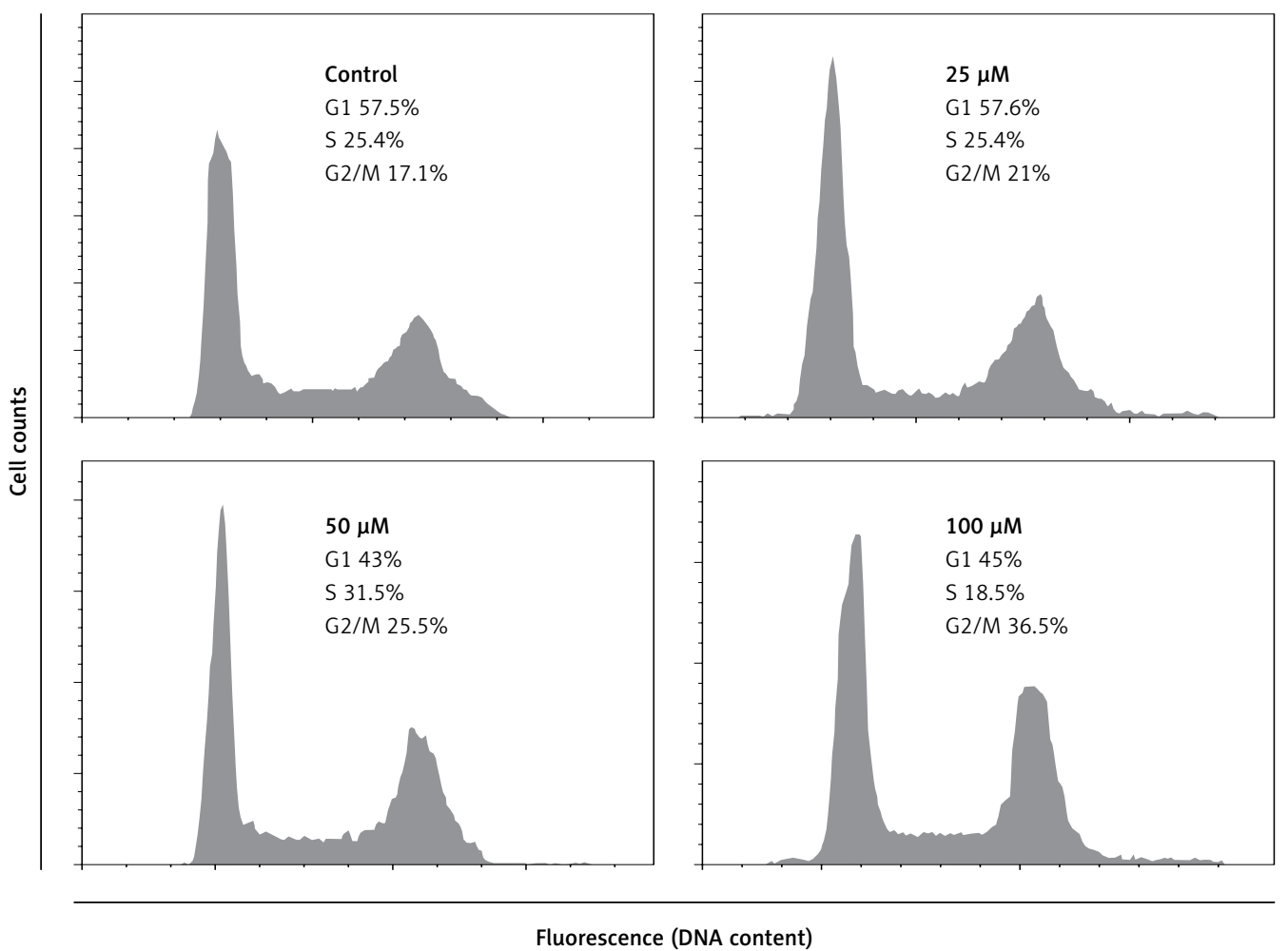

Figure 5. Effect of indicated doses of eriodictyol on cell cycle phase distribution of A549 cancer cells. All experiments are representatives of three biological replicates

A

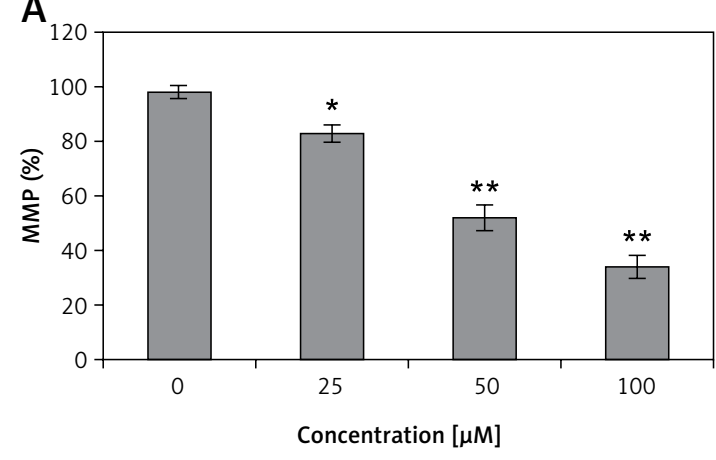

B

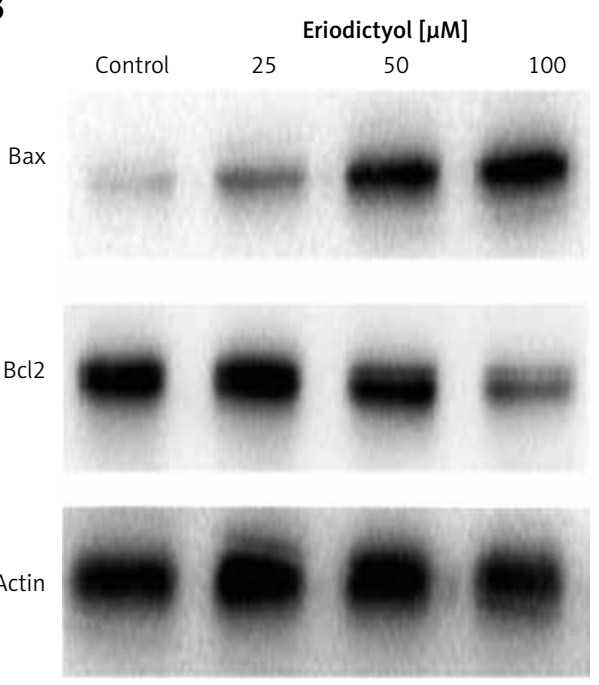

Figure 6. Effect of indicated doses eriodictyol on (A) mitochondrial membrane potential of A549 cancer cells, (B) expression of $\mathrm{Bax} / \mathrm{Bcl}-2$ by western blotting. All experiments are replicates of three biological replicates The values were considered significant at $p^{*}<0.05$ and $p^{* *}<0.01$. 
to the untreated control cells, eriodictyol-treated cells showed concentration-dependent downregulation of Bcl-2 and upregulation of Bax proteins, hence increasing the $\mathrm{Bax} / \mathrm{BCl}-2$ ratio and ultimately inducing apoptosis.

\section{Effect of eriodictyol on m-TOR/PI3K/Akt signalling pathway}

Whether eriodictyol could modulate the protein expression of the m-TOR/PI3K/Akt signalling pathway was evaluated using western blot analysis. The findings are shown in Figure 7 and indicate an interesting outcome. As compared to the untreated control cells, eriodictyol-treated cells showed concentration-dependent downregulation of $\mathrm{m}$-TOR and $\mathrm{pm}$-TOR proteins. It also caused downregulation of PI3K/Akt protein expression levels.

\section{Discussion}

Lung cancer is one of the deadly cancers occurring around the globe. Hundreds of thousands of patients are diagnosed with this disease annually [5]. Although existing treatment options exhibit decent clinical results, still hundreds of thousands of cancer-related deaths are attributed to lung cancer. Moreover, existing treatment options have severe side effects which badly influence the quality of life [6]. Nonetheless, development of drug resistance has made cancer very difficult to treat. Therefore natural products are known to have multiple targets and are able to suppress or activate complicated signalling pathways to inhibit cancer cell growth [7]. In the current study, eriodictyol showed potential growth-inhibiting activity against human lung A549 cancer cells, as was evident from the proliferation assay. Eriodictyol exhibited an $\mathrm{IC}_{50}$ of $50 \mu \mathrm{M}$ against the human A549 cells as compared to the $\mathrm{IC}_{50}$ of $95 \mu \mathrm{M}$ against the noncancerous FR2 cells, clearly indicating that eriodictyol is less toxic to normal cells. Several studies have reported that flavonoids are not toxic to normal cells and may therefore prove to be potential anticancer agents [9]. Flavonoids such as eriodictyol are regularly consumed in the human diet and are present at high concentrations in fruits, vegetables and other plant-derived foods, such as teas and other beverages and hence are considered non-toxic [10].

As reported previously, many drugs exhibit antiproliferative effects via induction of apoptosis. Several existing drugs have been reported to alter explicit apoptotic signalling pathways [9-14]. Additionally, drug resistance is partially explained by the potential of cancer cells to escape apoptosis [15]. It was observed that eriodictyol induces apoptosis in a concentration-dependent manner. Mitochondrial outer membrane permeability
(MOMP) is an important process involved in the apoptotic pathway. In the present study it was observed that eriodictyol showed a significant reduction in the MMP and exhibited a concentration-dependent pattern. Our results are consistent with studies carried out earlier [16]. Therefore the results suggest that eriodictyol may induce apoptosis by cumulative intracellular reduction of MMP. It has been reported that many anti-cancer drugs target cancer cells partially by causing reduction of MMP [17]. Analysis of apoptotic cell populations revealed that eriodictyol induces apoptosis and DNA damage in human lung cancer cells, as demonstrated by the comet assay. These observations are in agreement with previous studies wherein natural products such as isoliquiritigenin were found to inhibit cancer cell growth and induce apoptosis [18]. Flow cytometry using propidium iodide as a probe was used to study the effects of eriodictyol on cell cycle progression. Eriodictyol induced $\mathrm{G} 2 / \mathrm{M}$ cell cycle arrest and led to a significant increase of $\mathrm{G} 2 / \mathrm{M}$ cells dose dependently. Our results are consistent with previous studies wherein natural products have been reported to inhibit cell proliferation and induce cycle arrest in a dose-dependent manner [19]. Additionally, effects of eriodictyol on Bcl-2/Bax signalling were studied using western blot assay.

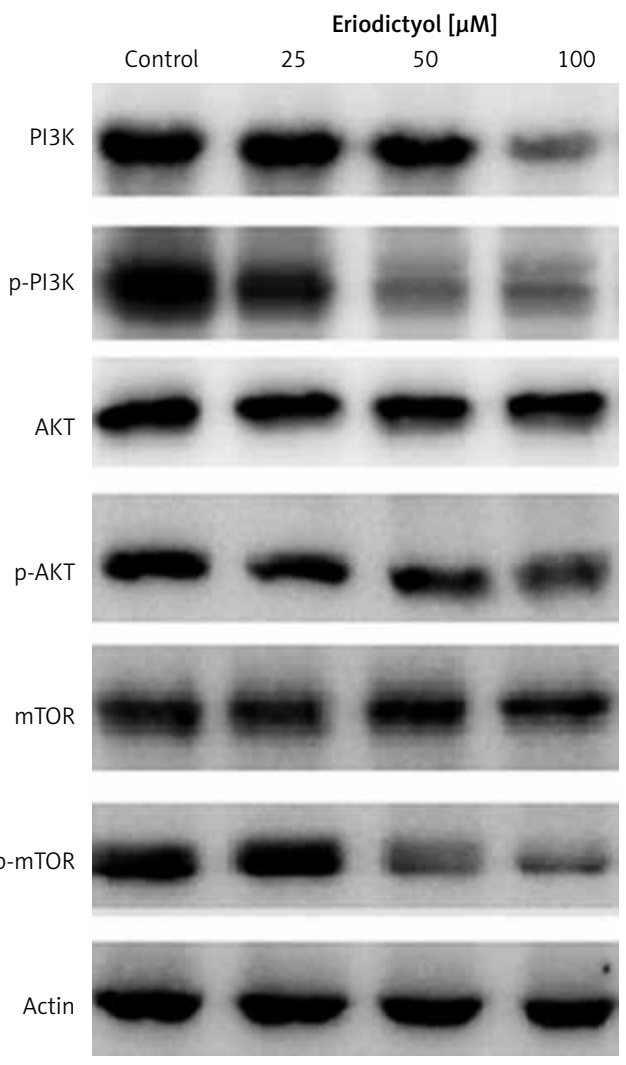

Figure 7. Effect of indicated doses of eriodictyol on key proteins of PI3K/AKT/mTOR signalling pathway. All experiments were carried out in triplicate 
The results showed eriodictyol acid-treated cells showed concentration-dependent downregulation of $\mathrm{Bcl}-2$ and upregulation of Bax proteins, ultimately inducing apoptosis. Members of the $\mathrm{BCl}-2$ family proteins, such as $\mathrm{Bcl}-2$, Bax and Bak, are believed to play key controlling roles in the execution of cell apoptosis. However, several studies have shown that Bcl-2 family proteins also aim at the apoptotic pathway $[19,20]$. Finally, the effect of eriodictyol on the $\mathrm{PI} 3 / \mathrm{AKT} / \mathrm{mTOR}$ signalling pathway was investigated and it was observed that it caused inhibition of a key protein of the pathway. These results are interesting since this target is considered important cancer chemotherapy.

Taken together, our results have shown that eriodictyol is a potent anti-cancerous molecule. Furthermore, flavonoids are generally non-toxic and can hence be used at higher concentrations in humans. The results of the present study pave the way for further evaluation of this molecule against more cell lines and under in vivo conditions.

In conclusion, in the present study, our data provide a framework for the construction of cell death pathways in A549 cells in response to eriodictyol by inducing apoptosis, regulating the $\mathrm{Bcl}-2 /$ Bax signalling pathway and mainly by inhibition of the PI3K/AKT/m-TOR signalling pathway. All of these contribute to the inhibition of growth of cancer cells, and eriodictyol might potentially serve as a potential candidate for cancer therapy.

\section{Acknowledgments}

Yong Zhang and Rui Zhang contributed to this work equally.

\section{Conflict of interest}

The authors declare no conflict of interest.

\section{References}

1. Dinda B, Debnath S, Harigaya Y. Naturally occurring iridoids. A review part 1. Chem Pharm Bull 2007; 55: 159-222.

2. Dinda B, Debnath S, Harigaya Y. Naturally occurring secoiridoids and bioactivity of naturally occurring iridoids and secoiridoids. A review part 2. Chem Pharm Bull 2007; 55: 689-728.

3. Nagaoka T, Banskota AH, Tezuka Y, et al. Selective antiproliferative activity of caffeic acid phenethyl ester analogues on highly liver metastatic murine colon 26-L5 carcinoma cell line. Bioorg Med Chem 2002; 10: 3351-9.

4. Albach DC, Grayer RJ, Jensen SR, Ozgokce F, Veitch NC. Acylated flavones glycosides from Veronica. Phytochemistry 2003; 64: 1295-301.

5. Sharma D, Newman TG, Aronow WS. Lung cancer screening: history, current perspectives, and future directions. Arch Med Sci 2015; 11: 1033-43.

6. Shi WY, Liu KD, Xu SG, et al. Gene expression analysis of lung cancer. Eur Rev Med Pharmacol Sci 2014; 18: 217-8.
7. Hsu YL, Kuo PL, Lin CC. Isoliquiritigenin induces apoptosis and cell cycle arrest through p53-dependent pathway in Hep G2 cells. Life Sci 2005; 77: 279-92.

8. Fulda S, Debatin KM. Targeting apoptosis pathways in cancer therapy. Curr Cancer Drug Targets 2004; 4: 569-76.

9. Lopez-Lazaro M. Flavonoids as anticancer agents: structure-activity relationship study. Curr Med Chem Anticancer Agents 2002; 2: 691-714.

10. Galati G, O'brien PJ. Potential toxicity of flavonoids and other dietary phenolics: significance for their chemopreventive and anticancer properties. Free Radic Biol Med 2004; 37: 287-303.

11. Romashkova JA, Makarov SS. NF-kappaB is a target of AKT in anti-apoptotic PDGF signalling. Nature 1999; 401: 86-90.

12. Chiang LC, Ng LT, Lin IC, Kuo PL, Lin CC. Anti-proliferative effect of apigenin and its apoptotic induction in human Hep G2 cells. Cancer Lett 2006; 237: 207-14.

13. Chiang JH, Yang JS, Ma CY, et al. Danthron, an anthraquinone derivative, induces DNA damage and caspase cascades-mediated apoptosis in SNU-1 human gastric cancer cells through mitochondrial permeability transition pores and Bax-triggered pathways. Chem Res Toxicol 2011; 24: 20-9.

14. Sun SY, Hail N, Jr Lotan R. Apoptosis as a novel target for cancer chemoprevention. J Natl Cancer Inst 2004; 96: 662-72.

15. Maitra R, Porter MA, Huang S, Gilmour BP. Inhibition of NFkappaB by the natural product Withaferin A in cellular models of cystic fibrosis inflammation. J Inflamm 2009; 6: 15.

16. Chipuk JE, Bouchier-Hayes L, Green DR. Mitochondrial outer membrane permeabilization during apoptosis: the innocent bystander scenario. Cell Death Diff 2006; 13: 1396-402.

17. Azuma M, Tamatani T, Ashida Y, Takashima R, Harada K, Sato M. Cisplatin induces apoptosis in oral squamous carcinoma cells by the mitochondria-mediated but not the NF-kappaB-suppressed pathway. Oral Oncol 2003; 39: 282-9.

18. Li Y, Zhao H, Wang Y, Zheng H, Yu W, Chai H. Isoliquiritigenin induces growth inhibition and apoptosis through downregulating arachidonic acid metabolic network and the deactivation of $\mathrm{PI3K} / \mathrm{Akt}$ in human breast cancer. Toxicol Appl Pharmacol 2013; 272: 37-48.

19. Abal M, Andreu JM, Barasoain I. Taxanes: microtubule and centrosome targets, and cell cycle dependent mechanisms of action. Curr Canc Drug Targs 2003; 3: 193-203.

20. Khursheed A, RatherM A, Rashid R. Plant-based natural compounds and herbal extracts as promising apoptotic agents: their implications for cancer prevention and treatment. Adv Biomed Pharma 2016; 34: 225-48. 